\title{
Pirâmide "holográfica": erros conceituais e potencial didático
}

\author{
"Holographic" pyramid: conceptual errors and didactic potential \\ Milton Schivani ${ }^{1,3}$, Gustavo Fontoura de Souza*2, Emanuel Pereira ${ }^{3}$ \\ ${ }^{1}$ Universidade Federal do Rio Grande do Norte, Departamento de Física, Natal, RN, Brasil \\ ${ }^{2}$ Instituto Federal de Educação, Ciência e Tecnologia do Rio Grande do Norte, Natal, RN, Brasil \\ ${ }^{3}$ Universidade Federal do Rio Grande do Norte, Mestrado Nacional Profissional em Ensino de Física, Natal, RN, Brasil
}

Recebido em 12 de Junho, 2017. Revisado em 01 de Novembro, 2017. Aceito em 06 de Novembro, 2017.

\begin{abstract}
A alusão aos hologramas é identificada em diferentes contextos para denominar diversos dispositivos e apresentações, a exemplo das imagens exibidas através das pirâmides "holográficas". Todavia, conforme apontamos neste artigo, as imagens exibidas por essas pirâmides, além de não serem hologramas de fato, não passam de imagens bidimensionais. Identificamos, entretanto, um rico potencial didático nas pirâmides "holográficas" para o ensino de Física, especialmente quando nos atentamos para a transição da curiosidade ingênua do educando em curiosidade epistemológica e para o ensino de determinados conceitos da óptica e da matemática. Assim, construímos uma pirâmide quadrangular utilizando chapas de acrílico e tecemos discussões sobre seu funcionamento. Por meio deste artigo, esperamos, dentre outras coisas, promover a consciência crítica dos docentes e educandos em geral frente aos artefatos tecnológicos em constantes mudanças ao seu redor, especialmente aqueles supostamente relacionados aos hologramas.
\end{abstract}

Palavras-chave: Hologramas, Pirâmides "Holográficas", Óptica, Curiosidade ingênua e epistemológica, Problematização.

\begin{abstract}
Allusion to holograms is identified in different contexts to refer to different devices and shows, like the images displayed by the pyramids "holographic". However, as we pointed out in this article, the images displayed by these pyramids, besides not being holograms in fact, are just two-dimensional images. We identified, however, a rich didactic potential in "holographic" pyramids for the teaching of Physics, especially when we consider the transition from the student's naive curiosity to epistemological curiosity and the teaching of certain concepts of optics and mathematics. Therefore, we built a quadrangular pyramid using acrylic plates and we made discussions about their operation. Through this article, we hope, among other things, to promote the critical awareness of teachers and students in the face of technological artifacts in constant changes around them, especially those considered as holograms.
\end{abstract}

Keywords: Holograms, Holographic Pyramids, Optics, Naive and Epistemological Curiosity, Problematization.

\section{Introdução}

A indústria cinematográfica, especialmente quando se trata de filmes de ficção científica e de ação, faz constantemente alusão a imagens tridimensionais que o grande público, geralmente, classifica como hologramas. Nesse universo ficcional, encontramos cenas e situações de filmes nos quais supostos hologramas são empregados para os mais diversos fins, por exemplo: Resident Evil: $O$ Hóspede maldito [1], quando a "rainha vermelha" conversa com os protagonistas; Star Wars Episode IV:A New Hope [2], nas mensagens transmitidas pelo robô R2D2; Prometheus [3] e Avatar [4], na exibição de mapas com informações geográficas e geológicas de uma determinada região investigada; e Homem de Ferro 2 [5], nas diversas situações em que a personagem Tony Stark

*Endereço de correspondência: gfontoura@gmail.com interage com seus sistemas que geram imagens virtuais. Quem não se recorda da cena em que esse protagonista "condensa" a imagem tridimensional de um modelo de elemento químico criado por ele e o segura com a ponta de seus dedos?

Além de nas telas dos cinema, também podemos encontrar menção aos hologramas em grandes eventos de premiação, campanhas de marketing, campanhas eleitorais, shows de música e até mesmo em campanhas em aeroportos para auxiliar no controle das filas de embarque. O Billbord Music Awrds (edição de 2014) e o Coachella Fest (edição 2012), por exemplo, surpreenderam boa parte do público ao exibirem no palco performances encenadas por cantores já falecidos, como Michael Jackson (1958 - 2009) e Tupac Shakur (1971 - 1996), respectivamente. Já os aeroportos de Manchester, no Reino Unido, e o de Luton, em Londres, não "ressuscitaram os mortos", mas 
geraram algumas polêmicas em meados de 2011 quando anunciaram uma possível redução de seu quadro de funcionários ao utilizarem assistentes virtuais para orientar os passageiros.

Já algumas campanhas de marketing e eventos corporativos, para divulgarem seus produtos por meio de supostas imagens holográficas, utilizam-se de dispositivos vulgarmente denominados "pirâmides holográficas' 1 . Diferente das imagens apresentadas nos shows e nas campanhas nos aeroportos, que possuem a altura de uma pessoa mediana, as imagens geradas através dessas pirâmides quadrangulares possuem pequenas proporções, geralmente não ultrapassam $50 \mathrm{~cm}$ de altura. Contudo, não deixam nada a desejar quanto à qualidade das imagens e quanto ao nível de sofisticação que podem alcançar. Essas pirâmides podem fornecer a nítida impressão de que o espectador está observando um objeto real e tangível. Em alguns casos, as imagens exibidas também geram a ilusão de interação com objetos concretos, além de apresentarem a noção de profundidade, a exemplo do caso ilustrado pela Figura 1 em que se observa uma garrafa de vidro de champanhe com rótulo, lacre e rolha.

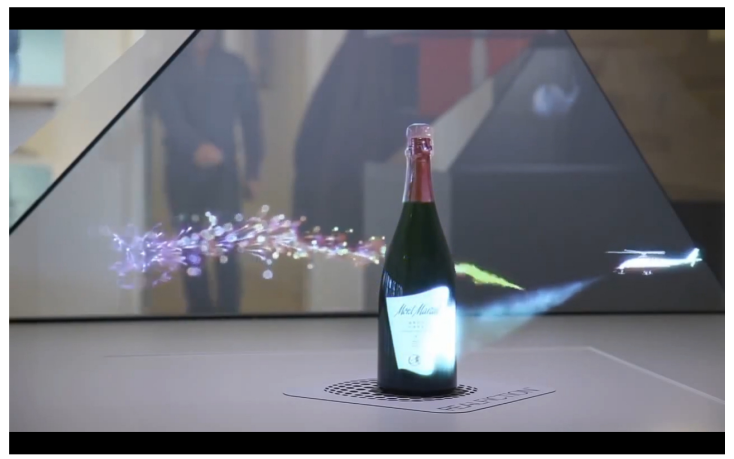

(a)

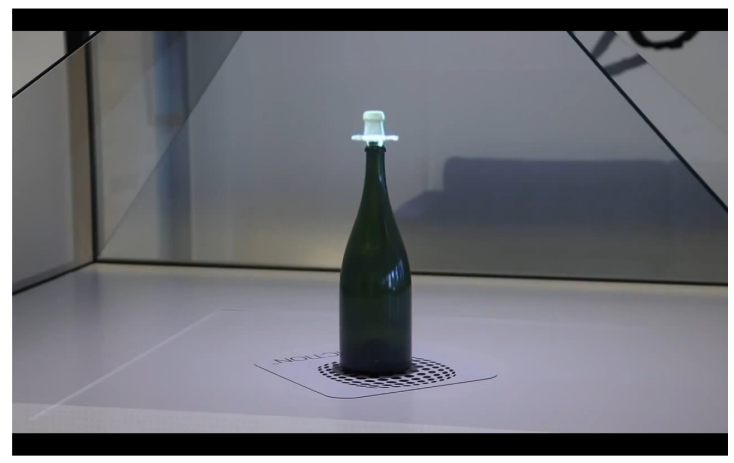

Figura 1: Garrafa de champanhe dentro de uma pirâmide quadrangular "holográfica". O lacre e o rótulo (a), bem como a rolha (b), não existem de fato enquanto objetos tangíveis. Fonte: Imagens obtidas por captura de tela (Print Screen) de vídeo disponível pelo canal Moon Media no Youtube em https://youtu.be/IOcscl5ZuF4 Acesso em 29 de março de 2017.

\footnotetext{
${ }^{1}$ Adotamos neste artigo o termo holográfica entre aspas para destacar que se trata de uma expressão com significado particular e usada de forma incorreta para designar as referidas pirâmides.
}

Tanto as cenas presentes nos filmes e séries quanto as imagens de possíveis hologramas, que encontramos em determinados eventos, têm o potencial de alavancar o imaginário popular e fomentar a curiosidade ingênua [6], especialmente do público jovem ávido por novidades tecnológicas. Essa curiosidade está associada ao saber de senso comum, a uma cultura primeira do indivíduo. Todavia, " [...] é a mesma curiosidade que, criticizando-se, aproximando-se de forma cada vez mais metodicamente rigorosa do objeto cognoscível, se torna curiosidade epistemológica." (ibidem, p. 31). Desse modo, como forma de promoção à transição da curiosidade ingênua para a curiosidade epistemológica, podemos tecer vários questionamentos, por exemplo: essas imagens de artistas, assistentes virtuais e objetos em geral podem mesmo ser consideradas como hologramas? Como se formam e quais são as propriedades que definem os hologramas? Toda vez que um palestrante usa uma ponteira laser para destacar uma parte do slide, se observa apenas um ponto de luz ou todo o feixe do laser? Se geralmente observamos somente o ponto de luz na tela, uma vez que para ver o feixe é necessário um anteparo para refletir a luz e atingir nossa visão, a exemplo da poeira suspensa no ar ou uma cortina de fumaça, como visualizar e interagir com supostos hologramas gerados por fontes de luz laser sem o auxílio de óculos ou telas especiais?

Como bem destaca o educador brasileiro Paulo Freire,

[...] a construção ou a produção do conhecimento do objeto implica o exercício da $\mathrm{cu}-$ riosidade, sua capacidade crítica de 'tomar distância' do objeto, de observá-lo, de delimitá-lo, de cindi-lo, de "cercar" o objeto ou fazer sua aproximação metódica, sua capacidade de comparar, de perguntar. ( [6], p. 85. Grifo do autor).

No item a seguir, apresentamos algumas definições conceituais e técnicas a respeito da concepção e do desenvolvimento dos hologramas, o que pode fomentar a curiosidade epistemológica frente as pirâmides "holográficas". Na sequência, apresentamos alguns erros conceituais quando se considera como holograma determinadas imagens exibidas em diferentes contextos. No caso das imagens produzidas por meio das pirâmides "holográficas", também tratamos dos fenômenos de reflexão e refração sofridos pela luz ao atingir as superfícies que formam as faces da pirâmide, evidenciando não se tratar de hologramas e muito menos de imagem tridimensional.

\section{Hologramas ou simples projeções bidimensionais?}

A concepção dos hologramas surge originalmente no campo da microscopia eletrônica e com a necessidade de se registrar em chapas fotográficas informações sobre a fase das ondas na difração de raios $\mathrm{X}$ e em outras 
situações análogas. A concepção teórica para o desenvolvimento dos hologramas remete à reconstrução das frentes de onda oriundas do objeto e registradas em uma chapa fotográfica que, quando vistas por um observador, dão a nítida impressão de se estar observando o próprio objeto [7, [8. Essa técnica é creditada ao engenheiro Dennis Gabor (1900-1979) e lhe rendeu o prêmio Nobel de Física de 1971.

A Figura 2 apresenta de forma simplificada a montagem clássica para o processo de produção de um holograma.

O feixe de luz, nesse caso um raio laser, é dividido em duas partes. Uma das partes reflete no objeto e atinge a placa holográfica, como uma espécie de fotografia. A outra parte serve como feixe de referência e não atinge o objeto. É encaminhada para a placa fotográfica causando um padrão de interferência. Desse modo, o filme registra tanto a intensidade da luz difundida pelo objeto quanto a diferença de fase entre o feixe de referência e o feixe de luz refletida pelo objeto, formando o holograma. Quando o holograma é iluminado apenas pelo raio de referência, produz réplicas das frentes de ondas que foram refletidas pelo objeto original, formando uma imagem com todas as informações tridimensionais fornecidas pelo objeto real e que foram registradas no holograma [9], [10].

Apesar da concepção original de Gabor, a holografia (do grego, "registro completo") ganhou destaque somente após outros pesquisadores colaborarem para seu desenvolvimento e produzirem hologramas de maior qualidade. Além do próprio Dennis Gabor, podemos destacar ainda Yuri Denisyuk (1927-2006) e Emmett Leith (1927-2005) como protagonistas no desenvolvimento da holografia [7]. Denisyuk, inspirado na obra de ficção científica Stellar Ships, escrita em 1944 pelo russo Ivan Antonovich Yefremov (1908-1972), criou no início da década de 1960 a técnica de holograma por reflexão, permitindo a reconstrução da imagem com luz branca e possibilitando visualizar o holograma com uma lâmpada incandescente

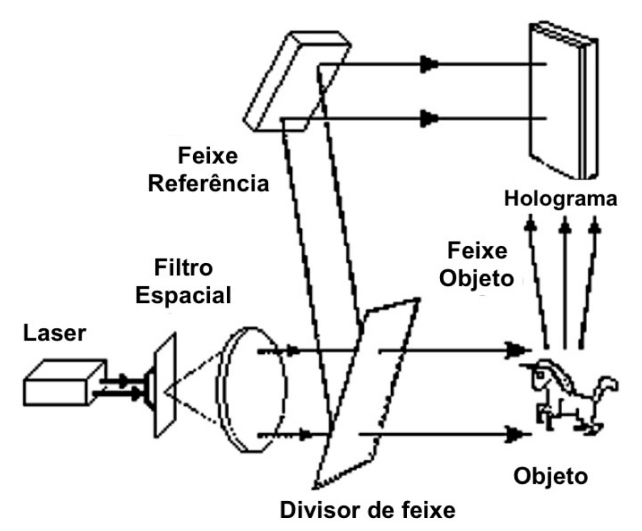

Figura 2: Montagem clássica para o processo de produção de um holograma. Fonte: Laboratório de Ensino de Óptica do Instituto de Física Gleb Wataghin da Unicamp. (http://sites.ifi.unicamp.br/laboptica/holografia-2/) Acesso em 02 de maio de 2017. comum. Leith, por sua vez, em colaboração com o engenheiro eletricista Juris Upatnieks (1936- ) e com o emprego de lasers comerciais já disponíveis em sua época, desenvolveram o holograma fora de eixo, em que as ondas de referência e aquelas provenientes do objeto incidem sobre a mesma placa fotográfica, mas formando um determinado angulo entre elas. Conforme ressalta Beléndez ( 7$],$ p. 9),

Usando este novo sistema de registro, as imagens virtuais e reais estão separadas angularmente na etapa de reconstrução e o problema de Gabor dos fantasmas está resolvido. Esta técnica de holografia fora do eixo teve um impacto enorme e foi crucial para o avanço da holografia como uma tecnologia realmente útil ( 7], tradução livre).

Sem uma fonte de luz coerente como as fornecidas pelos lasers, os trabalhos de Leith e demais investigações no campo da holografia seriam inviabilizados. Dessa maneira, não podemos deixar de lado a própria criação do laser (light amplification by stimulated emission of radiation), em 1960 pelo físico Theodore Harold Maiman (1927-2007), como elemento fundamental para o desenvolvimento dos hologramas. Foge do escopo deste trabalho o resgate histórico do desenvolvimento da holografia e suas técnicas de produção. Todavia, àqueles que desejarem se aprofundar nesse aspecto indicamos os textos de Beléndez 7] e Saxby [11.

Essencialmente, quanto ao conceito de holograma, podemos afirmar que:

Para o físico, um holograma é um registro da interação de dois feixes de luz mutuamente coerentes, sob a forma de um padrão microscópico de franjas de interferência. Para o leigo bem informado, é um filme fotográfico ou placa que foi exposto à luz laser e processado de modo que quando iluminado adequadamente produz uma imagem tridimensional. Para os menos bem informados é apenas algum tipo de fotografia tridimensional. ( [11], p. 3. Tradução livre).

No holograma ilustrado pela Figura 3 há uma nítida impressão de se tratar de um objeto real, ou seja, parece que estamos observando as próprias moedas. Contudo,

[...] na realidade, o objeto não existe na placa holográfica, mas cria a ilusão óptica da sua presença e o holograma envia ao espectador ondas luminosas idênticas às refletidas pelo objeto real. ( 12$]$, p. 1)

No Brasil, destacamos os trabalhos do pesquisador José Joaquín Lunazzi no desenvolvimento das holoimagens, imagens tridimensionais completas reproduzidas por um 


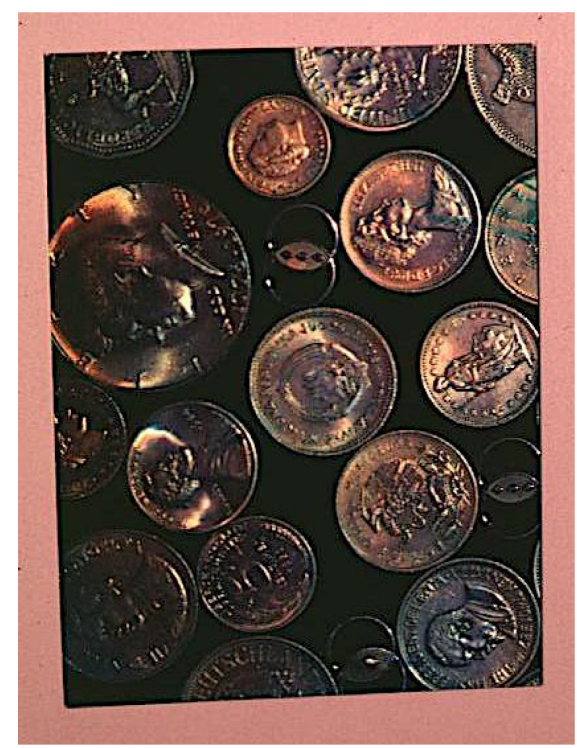

Figura 3: Holograma de moedas em filme Polaroid Photopolymer, produzido em 1985 nos laboratórios de investigação da Polaroid Corporation, Cambridge. Fonte: MIT Museum, objeto código MOH-1985.67 (https://webmuseum.mit.edu). Acesso em 29 de março de 2017.

holoprojetor em uma tela holográfica (uma rede de difração com propriedades focalizadoras) [13, 14], 99, [15]. Lunazzi destaca que a holoprojeção combinada com outras técnicas, como a ampliação de hologramas por meio de luz branca, abre caminhos para o cinema holográfico, codificando uma sequência contínua de perspectivas de uma cena e projetando-as na tela holográfica 13 .

Apesar dos avanços das atuais pesquisas sobre produção de hologramas dinâmicos, capazes de calcular a difração e o padrão de interferência de forma dinâmica e em tempo real [16], ainda não possuímos a tecnologia necessária para gerar "vídeos holográficos" projetados no espaço com possibilidades de interação com o observador, a exemplo daqueles exibidos nos filmes de ficção científica anteriormente citados.

Assim, constatamos que a palavra holograma vem sendo empregada comumente de forma errônea para designar uma vasta gama de imagens e animações, incluindo aquelas observadas por meio das pirâmides "holográficas". Por exemplo, em texto online atribuído à redação da revista de divulgação científica Galileu, a popstar virtual japonesa Hatsune Miku foi classificada de forma equivocada como um "holograma 3D" [17]. No texto, a referida revista afirmou que:

Agora, na forma de holograma tridimensional, Hatsune Miku arrasta multidões para seus shows em várias cidades do Japão. Os fãs de Hatsune, reprodução holográfica de uma garota de 16 anos, agitam barras luminosas e gritam durante o show como se a artista fosse real. [...] Esta é a primeira vez que um holograma tão grande é usado de forma artística desta maneira. (ibidem. Grifo nosso).

Em nota publicada no jornal Correio Popular, o professor Dr. José Joaquín Lunazzi, do Instituto de Física "Gleb Wataghin" (IFGW) da Unicamp, esclarece que é "[...] bom lembrar que um holograma gera imagens tridimensionais, não chapadas em uma tela, quem senta nas primeiras fileiras nota a diferença" 18. Nessa nota, Lunazzi refere-se a outra suposta apresentação holográfica, promovida por um shopping de São Paulo em 2013.

Em 2011, a campanha promovida pelo aeroporto de Luton, em Londres, chegou ao ponto de nomear seus dois assistentes virtuais (que não são hologramas conforme foi atribuído) de Holly e Graham, um trocadilho com a palavra hologram. A BBC News online, perpetuando a noção equivocada de holograma, produziu ainda uma matéria intitulada "London Luton Airport has become one of the first in the world to introduce holographic announcers" [Aeroporto de Luton, Londres, tornou-se um dos primeiros no mundo a introduzir apresentadores holográficos] sem explicar que os assistentes não eram de hologramas de fato 19.

Em 2015, uma campanha de conscientização desenvolvida na Rússia pela agência digital Bird Strategy utilizou um suposto holograma que despertou a curiosidade e gerou alguns sustos nos motoristas que tentaram estacionar em vaga reservada para cadeirantes. Os motoristas que não tinham a autorização estampada no para-brisas do carro eram surpreendidos pela imagem de um cadeirante, localizado bem no meio da vaga e pedindo para parar o carro. O vídeo oficial dessa campanha, no qual é possível perceber a reação dos motoristas abordados pela imagem do cadeirante, já foi visualizado mais de cinco milhões de vezes. Além do próprio título do vídeo, divulgado na mídia social como "In this mall, holograms of disabled people appear if you try to park in their space" [Neste shopping, hologramas de pessoas com deficiência aparecem se você tentar estacionar em seu espaço], vários sites, blogs, jornais e programas de televisão ao redor do mundo repercutiram essa campanha como se se tratasse de emprego de hologramas. O próprio vídeo da campanha explica rapidamente como a imagem foi gerada, fazendo uso de uma cortina de gotículas de água e de um projetor convencional [20]. Todavia, a explicação apresentada por esse vídeo pode gerar nas pessoas em geral noções errôneas sobre a formação de um holograma, como se um holograma fosse uma simples projeção e pudesse ser gerado através da luz refratada por uma cortina de gotículas de água.

Nas campanhas de 2017 para presidente da França, jornais de diversas partes do mundo noticiaram, de forma também equivocada, que o candidato de extrema-esquerda Jean-Luc Melenchon esteve discursando em dois lugares ao mesmo tempo (Lyon e Paris) graças a uma tecnologia de "holograma 3D". O equívoco decorre da técnica empregada por esse candidato e por aqueles que exibiram as performances de Michael Jackson, Tupac Shakur e 
Hatsune Miku, citados anteriormente, pois ela não gera um holograma. Trata-se de uma técnica bem conhecida pelos ilusionistas, denominada de "Fantasma de Pepper", popularizada no Brasil como a "Casa de Monga" 21], 22]. Essa técnica foi criada pelo químico inglês John Henry Pepper (1821-1900) ao aperfeiçoar conceitualmente um dispositivo produtor de imagens ópticas virtuais desenvolvido pelo engenheiro civil Henry Dircks (1806-1873). Trata-se de uma simples projeção da imagem de um objeto oculto em uma superfície transparente. Essa superfície ou película precisa estar inclinada e iluminada de tal forma a refletir a imagem do objeto que está oculto para um observador externo, nesse caso, a plateia.

As imagens observadas através das pirâmides, classificadas erroneamente de holográficas, também se utilizam da técnica de Pepper. São imagens bidimensionais e não hologramas como são definidas vulgarmente, culminando essa designação em um erro conceitual. Conforme ilustrado pela Figura 4 a imagem original é exibida por um display (TV, smartphone, tablete ou monitor, por exemplo) ou projetor que, por sua vez, é refletida pelas faces da pirâmide.

No caso das pirâmides "holográficas", a imagem exibida no display possui quatro segmentos formando um "X". A imagem contida em cada segmento é então refletida pela respectiva face da pirâmide que esteja alinhada com esse segmento. A face central do display deve ser posicionada no topo da pirâmide e o conjunto pirâmide-display pode ser disposto com a base da pirâmide voltada para cima ou para baixo. A imagem de cada segmento pode ser única, ou seja, apresentar uma mesma perspectiva, ou múltipla, na qual cada face exibe uma perspectiva particular (por exemplo: dianteira, traseira, direita e esquerda), ampliando consideravelmente a ilusão de tridimensionalidade. Essas imagens ou vídeos projetados nas faces da pirâmide são encontradas facilmente nas mídias sociais. Compõem vídeos dos mais diferentes tipos, desde desenhos animados e objetos virtuais até simulações gráficas e propaganda de produtos comerciais, basta fazer uma busca por Pyramid Hologram Screen, por exemplo.

A construção dessas pirâmides por estudantes e professores e sua utilização para o ensino de física na educação básica, técnica ou superior podem apresentar questões e problemas que as tornam ricos instrumentos didáticos.

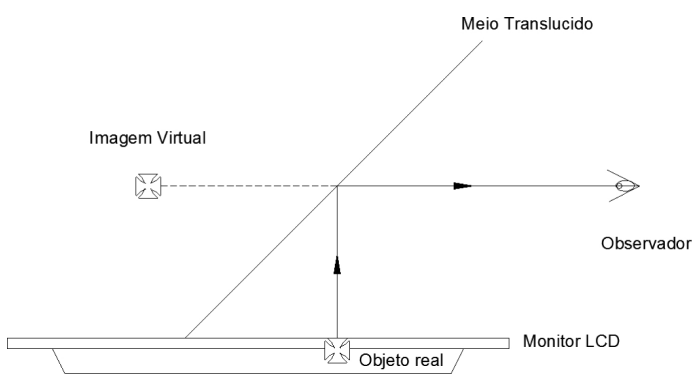

Figura 4: Esquema geral da projeção das imagens observadas através das pirâmides "holográficas". Fonte: Autoria própria.
Conforme será discutido mais adiante, a ilusão de tridimensionalidade experimentada pelo observador em geral e a construção das próprias pirâmides podem fomentar o ensino e o emprego de conceitos matemáticos e da óptica geométrica de forma problematizadora e contextualizada.

\section{O potencial didático das pirâmides "holográficas"}

É inegável o aspecto lúdico que carregam as ilusões de óptica em geral e seu potencial para despertar a curiosidade dos indivíduos de diferentes faixas etárias e níveis de escolaridade. Medeiros (21] p. 333) destaca que

[...] as ilusões de óptica poderiam ser úteis, não apenas no ensino da própria Óptica, mas igualmente, para auxiliar os estudantes no desenvolvimento dos processos de observação, comunicação, controle de variáveis, formulação de hipóteses, coleta e interpretação de dados.

Todos esses pontos estão presentes quando buscamos respostas para, por exemplo, como são formadas as imagens e quais são os fatores determinantes para se produzir uma imagem maior através das pirâmides "holográficas"? Essa questão pode lançar o estudante num verdadeiro desafio, no qual sua curiosidade ingênua poderá ser estimulada a transpor barreiras, tornando-se cada vez mais crítica e epistemológica, ou seja, buscando uma explicação mais completa e aprofundada sobre determinados aspectos daquele objeto foco de sua curiosidade inicial [6].

O educando pode ser estimulado inicialmente fomentando seu desejo de reprodução desse ou daquele artefato e fenômeno que despertou sua curiosidade ingênua. No caso das pirâmides "holográficas", não faltam nas redes e mídias sociais esquemas e procedimentos ensinando como desenvolver esses mecanismos. É possível, por exemplo, sua confecção fazendo uso de diferentes materiais e a um custo reduzido em comparação aos de uso comercial (que podem empregar películas ou filmes de projeção de alta qualidade e propriedades ópticas especiais). Ao se utilizar pequenos displays, como smartphones entre 4,5" e 6", as pirâmides quadrangulares construídas com finas lâminas de transparência (aquelas usadas nos retroprojetores) ou folhas de acetato transparentes em geral são as mais indicadas, com dimensões que não ultrapassam $6,0 \mathrm{~cm}$ de aresta da base e $3,5 \mathrm{~cm}$ de aresta lateral (Figura 5 ).

Dependendo da qualidade das películas, do display, da luminosidade ambiente e do ângulo de observação, essas pirâmides podem apresentar excelentes resultados visuais, exibindo imagens nítidas que podem causar a real sensação de se observar um objeto tridimensional em seu interior. Fazendo uso desse sistema, já é possível iniciar diversos questionamentos e investigações preliminares, a exemplo daqueles sobre a natureza da imagem observada na face da pirâmide ou sobre o porquê do formato piramidal. Todavia, quando nos questionamos sobre 


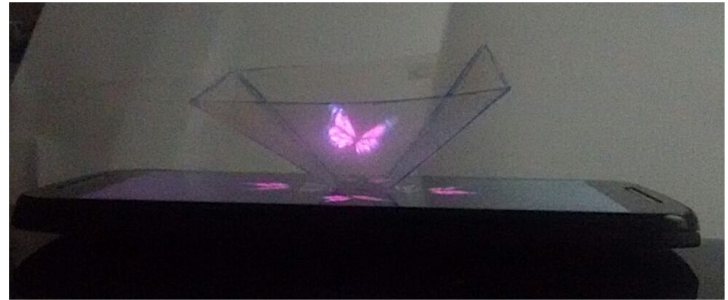

Figura 5: Pirâmide quadrangular "holográfica" para uso em smartphones e tabletes construída com folha de transparência para retroprojetores. Fonte: Autoria própria.

os fatores determinantes para se produzir uma imagem maior e mais nítida através das pirâmides "holográficas", talvez esse seja o momento no qual nos deparamos com seu maior potencial, em termos didáticos, de pleno fomento a transição da curiosidade ingênua para a epistemológica. Inicialmente, pode parecer que não há maiores dificuldades e implicações físicas no desenvolvimento de pirâmides maiores, mas isso não é verdade. Ao construir essas pirâmides, na tentativa de se produzir imagens maiores e mais nítidas com base na técnica de Pepper, alguns fenômenos ópticos se tornam mais acentuados e a construção da pirâmide pode se tornar didaticamente mais interessante e desafiadora.

\subsection{A problematização inicial}

O público em geral que contempla as referidas pirâmides pode se fascinar em decorrência de uma sensação de imaterialidade e flutuação da imagem observada, decorrente também da falta de percepção, por parte do observador, do display responsável pela projeção da imagem. Mas esse mistério da formação das imagens "holográficas", aparentemente tridimensionais e presentes no interior das pirâmides, pode ser resolvido bloqueando-se com a mão ou com uma folha de papel a imagem de um dos quatro segmentos projetados pelo display. Ao bloquear no display a imagem desse segmento, a face da pirâmide que está alinhada com ele não mais exibirá a imagem para o observador que esteja posicionado de frente a ela. Em seguida, pode-se alterar os segmentos bloqueados e a posição do observador, evidenciando-se tratar de uma imagem refletida, assim como o reflexo da nossa imagem quando olhamos para um espelho plano. Tanto a imagem observada no espelho plano quanto aquela refletida pelas faces da pirâmide são imagens virtuais, ou seja, se formam do prolongamento dos raios luminosos. Além disso, dependendo do público e do seu nível de instrução, essas observações podem ser confrontadas com as definições e esquemas de produção dos hologramas, conforme discutido anteriormente, destacando-se as particularidades dos hologramas.

Construímos uma pirâmide de base quadrada com chapas de acrílico transparente como especificado pela Figura 6 .

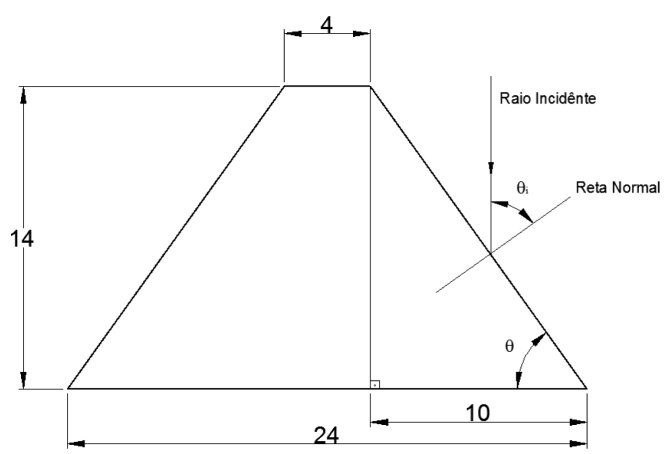

Figura 6: Dimensões (em centímetros) de uma das faces da pirâmide construída com chapas de acrílico de $4,0 \mathrm{~mm}$ de espessura. Fonte: Autoria própria.

Foram respeitadas as mesmas proporções da pirâmide usada no smartphone (Figura 5), com a qual obtivemos bons resultados. Mas ficamos desconcertados quando ligamos o display, um monitor de 14,1", e visualizamos as imagens. Conforme mostra a Figura 7 , produziu-se uma duplicata da imagem, causando uma espécie de efeito de sobreposição defasado de uma mesma imagem.

Tentamos alterar o nível da iluminação interna da pirâmide em relação ao meio externo e vice-versa, mas as imagens duplicadas continuavam aparecendo. Onde estava o problema? Quais variáveis e fatores físicos estavam causando essa defasagem? Havia algum fenômeno óptico em particular responsável pela geração das imagens observadas? Essas questões podem perfazer didaticamente a problematização, que

[... consiste na construção de situações-problema que irão estruturar as situações de aprendizagem, dando-lhes um significado percebido pelos alunos [...] (23, p. 42).

Demétrio Delizoicov [24], 25], após reflexões e estudos sobre a transposição da concepção freiriana de educação para o ensino de ciências, bem como inspirado em outros pensadores e obras, coloca a problematização como eixo estruturador da atividade docente auxiliado através do que se denominou de momentos pedagógicos, quais sejam: a) problematização inicial; b) organização do conhecimento; c) aplicação do conhecimento.

A problematização inicial visa propiciar um distanciamento crítico do educando frente as situações postas para discussão, objetiva essencialmente aguçar explicações aparentemente contraditórias ou limitadas para a compreensão e resolução do problema proposto. Destacamos que o surgimento da imagem duplicada nesse contexto pode compor principalmente a problematização inicial, revelando-se um potencial didático do uso dessas pirâmides em aulas de física.

A etapa de organização do conhecimento consiste na tomada de consciência do problema e dos conhecimentos necessários para solucioná-lo. Nesta etapa, é necessário o surgimento do confronto entre os conhecimentos intuiti- 


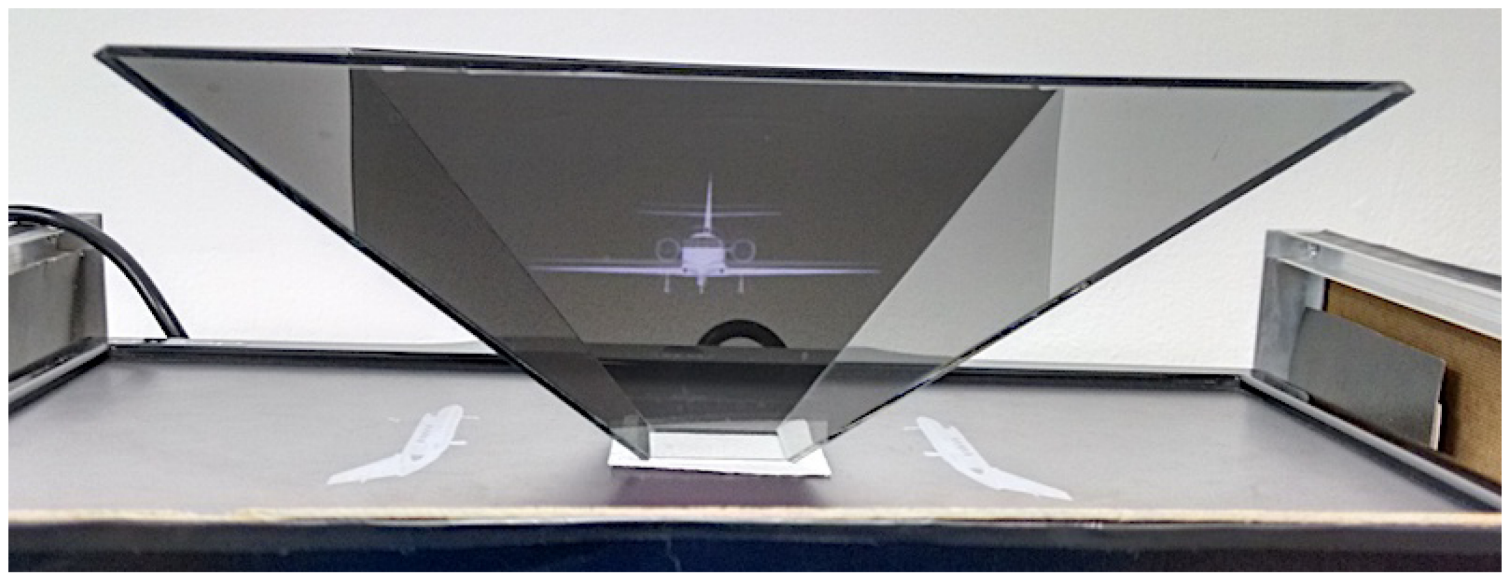

(a)

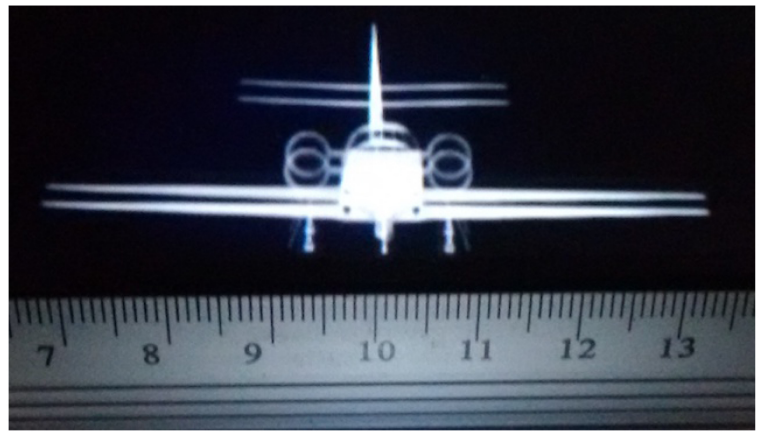

(b)

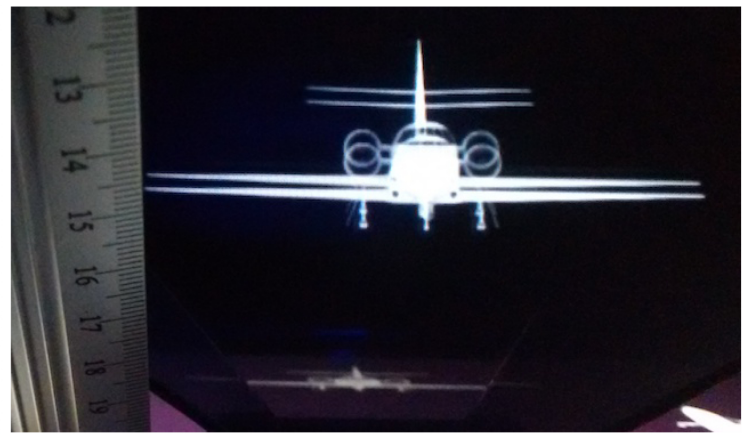

(c)

Figura 7: Imagem obtida com uma pirâmide de acrílico e um monitor LCD de 14,1". a) Registro completo da pirâmide em luz ambiente. b) e c) Imagem de um avião refletida por uma das faces da pirâmide. O registro foi feito em ambiente fechado e com luz proveniente apenas do monitor. Fonte: Autoria própria.

vos e prévios do aluno e os conhecimentos especializados do professor.

Por sua vez, na aplicação do conhecimento será avaliado a amplitude e alcance dos novos conhecimentos apropriados pelos estudantes, tanto para analisar e interpretar as situações postas na problematização inicial quanto outras questões e situações que podem ser compreendidas pelo mesmo conhecimento. Assim, os alunos podem adquirir um segundo nível de sistematização do conhecimento, buscando estendê-lo para outras questões e situações de mesma natureza. Isso é importante, pois a aplicação do conhecimento deixa de ser um exemplo do conteúdo ensinado e passa a ser uma ferramenta de pensamento para reflexão [24], 25], [26].

Conforme trataremos no item a seguir, ao investigar o problema da imagem duplicada e buscar sua solução, nos lançamos, de forma quase que natural, na referida organização e aplicação do conhecimento, o que realçou o potencial didático das referidas pirâmides. Além de nos depararmos com determinados conceitos da óptica geométrica e da matemática, observamos que estávamos imersos em diversos fatores científicos que, dependendo do nível de ensino, poderiam ser explorados em sala de aula, tais como formulação de hipóteses, coleta e interpretação de dados, testes e controle de variáveis.

\subsection{O problema das múltiplas reflexões}

Para melhor compreender o surgimento das imagens duplicadas e defasadas apresentado anteriormente, é preciso discutir inicialmente a construção da pirâmide, ou seja, suas dimensões e composição. O raio de luz que incide sobre as faces da pirâmide sofrerá desvio por reflexão e refração em função do ângulo de incidência, das dimensões e do tipo de material empregado na construção da pirâmide (acrílico, vidro, polímeros, etc.).

Para garantir a estabilidade da estrutura ao ampliar o tamanho da pirâmide, é necessário construí-la usando materiais mais rígidos. Assim, optamos pelo emprego de chapas de acrílico com 4,0mm de espessura, especialmente por ser mais leve e oferecer menos risco de acidentes quando comparado com o vidro.

Permeando o momento da organização do conhecimento, levantamos a hipótese de que a segunda imagem formada decorre de um processo de reflexão interna e refração do raio incidente $\left(R_{i}\right)$, resultando no raio $R_{r l r}$, como mostra a Figura 8

Efetuamos a previsão teórica de quantos centímetros a imagem gerada pelo segundo processo de reflexão estará defasada em relação a primeira, ou seja, determinamos o valor teórico esperado para a distância $d$ (segmento $\overline{E F}$ ) 


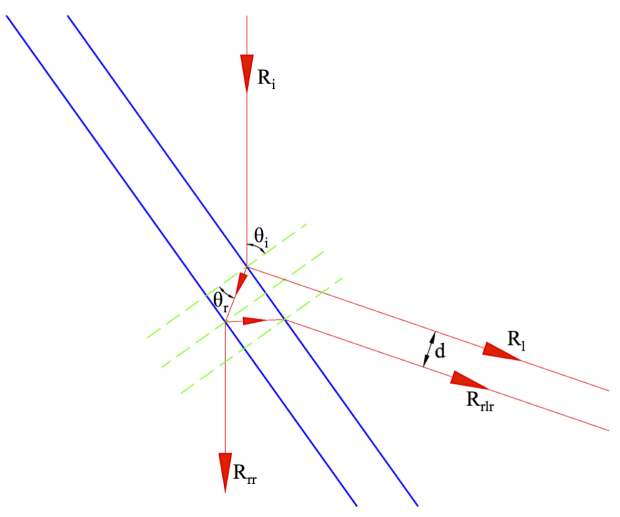

Figura 8: Esquema simplificado do processo de reflexão e refração dos feixes de luz que atingem as faces da pirâmide. Fonte: Autoria própria.

perpendicular entre os raios paralelos $R_{l}$ e $R_{r l r}$ como detalhado pela Figura 9

Segue-se que, dado as dimensões da pirâmide como explicitado anteriormente, temos o ângulo de incidência $\theta_{i}$ igual ao ângulo da base do triângulo (equação 1 ).

$$
\theta_{i}=\arctan \left(\frac{14}{10}\right)=54,46^{\circ}
$$

Aplicando-se a lei de snell-descartes, de acordo com a equação 2 , temos o ângulo de refração $\theta_{r}$, que corresponde a $31,10^{\circ}$.

$$
\begin{array}{r}
n 1 \operatorname{sen} \theta_{i}=n 2 \operatorname{sen} \theta_{r} \\
1 \operatorname{sen}\left(54,46^{\circ}\right)=1,49 \operatorname{sen} \theta_{r} \\
\theta_{r}=33,10^{\circ}
\end{array}
$$

De acordo com o triângulo interno formado pela superfície de entrada, raio refratado e reta normal (segmento $(\overline{A C F})$, figura 9 , calcula-se a distância $x$ conforme equação 3

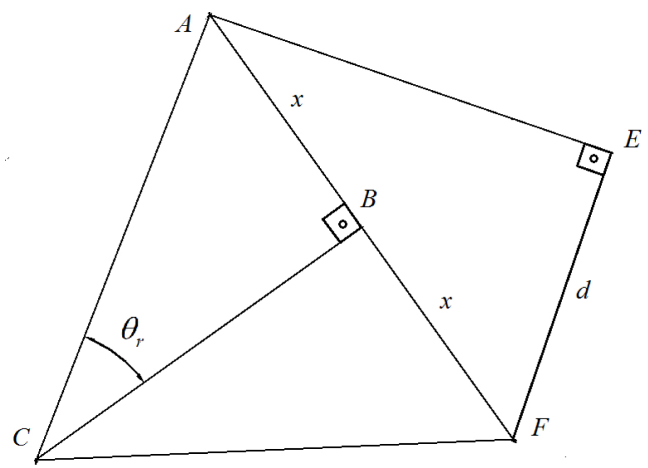

Figura 9: Geometria decorrente da refração e reflexão interna. $O$ raio de luz incidente é refletido (segmento $(\overline{A E})$ ), refratado (segmento $(\overline{A C})$ ) e refletido internamente (segmento $(\overline{C F})$ ) pela chapa de acrílico transparente (espessura indicada pelo segmento $(\overline{B C}))$. Fonte: Autoria própria.

$$
\begin{array}{r}
\tan \left(33,10^{\circ}\right)=\frac{x}{4 m m} \\
x=4 \cdot \tan \left(33,10^{\circ}\right)=2,60 \mathrm{~mm}
\end{array}
$$

Como a distância entre os raios $R_{l}$ e $R_{r l r}$ na parede externa da pirâmide é $2 \mathrm{x}$, teremos que o segmento $(\overline{A B F})$ resulta em 4,82mm. Assim, a distância $d$, perpendicular entre os raios $R_{l}$ e $R_{r l r}$, é calculada pela simetria da reflexão regular, conforme equação 4

$$
\begin{array}{r}
\operatorname{sen}\left(90^{\circ}-54,462^{\circ}\right)=\frac{d}{2 x} \\
d=2 \cdot x \cdot \operatorname{sen}\left(35,538^{\circ}\right) \\
d=3,02 \mathrm{~mm}
\end{array}
$$

Esse desvio de aproximadamente $3,02 \mathrm{~mm}$ pode ser verificado fazendo uso de uma fonte de luz laser. O aparato experimental foi disposto seguindo, de maneira geral, o esquema ilustrado anteriormente (Figura 4) e fizemos uso da pirâmide nas dimensões especificadas pela Figura 6 Assim, como mostra a Figura 10, obtivemos um valor experimental de aproximadamente $3,0 \mathrm{~mm}$ para a distância perpendicular entre os feixes $R_{l}$ (ponto de luz vermelho do lado esquerdo) e $R_{r l r}$ (ponto de luz vermelho do lado direto).

Desse modo, concluímos que a produção da dupla imagem é decorrente de um desvio do raio incidente ao sofrer reflexão interna e refração, passando do ar para o acrílico e do acrílico para o ar. Devido a espessura do acrílico $(4,00 \mathrm{~mm})$, o desvio decorrente desse processo se torna mais acentuado e perceptível a olho nu conforme foi calculado e mensurado. Mesmo pirâmides construídas com folhas de acrílicos extraídas de caixas de CD (Compact Disc), que possuem espessura na ordem de $1,4 \mathrm{~mm}$, apresentam esse efeito de duplicata da imagem. Todavia, por que as imagens observadas através das pirâmides "holográficas" comerciais, como aquela ilustrada anteriormente pela Figura 11. presentes em diferentes feiras e exposições, apresentam imagens nítidas e de grandes proporções, sem nenhum efeito de duplicata? Como o problema da reflexão interna foi solucionado?

\subsection{Reduzindo a reflexão interna}

Essa etapa permeia o momento de aplicação do conhecimento, tanto para resolver o problema das imagens

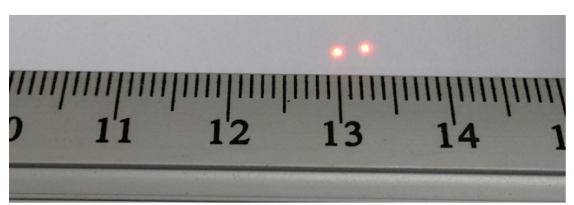

Figura 10: Desvios sofridos pelos raios de luz. O ponto de luz da esquerda remete a primeira reflexão $R_{l}$ e o da esquerda a reflexão interna $R_{r l r}$ após o feixe de luz sofrer refração. Fonte: Autoria própria. 
duplicadas e defasadas quanto para avaliar o conhecimento adquirido na compreensão de outros cenários e questões de natureza similar.

Atravs das mídias sociais, analisamos vídeos de diversas pirâmides com projeções variadas, desde representação de planetas e de objetos abstratos até propaganda de aparelhos de telefones e refrigerantes. Algumas pirâmides pareciam ser compostas por materiais com alta qualidade óptica ou películas especiais, como aquelas denominadas Rear Projection Film que permitem uma maior captura da luz projetada. Focamos nas pirâmides que aparentavam ter dimensões semelhantes daquelas com as quais já estávamos trabalhando. Na maioria dos vídeos analisados um aspecto ficou evidente, as superfícies das pirâmides não eram totalmente transparentes. Isso nos sugeriu a ideia de se utilizar películas reflexivas, como aquelas presentes em janelas de carros e portas de vidro. Tais películas poderiam reduzir a iluminância da segunda imagem, reduzindo o efeito de duplicata. Diferente da intensidade luminosa, iluminância, dado em Lux, refere-se a "quantidade de luz" incidente sobre um determinado ponto da superfície, ou seja, relaciona-se à densidade da intensidade luminosa e pode ser mensurada por meio de um luximetro.

Utilizamos uma película automotiva genérica encontrada e classificada no comércio local como sendo \#2. Ao verificarmos com um luxímetro (Luxímetro Digital Lux Meter, modelo MLM-1011) a iluminância decorrente da luz transmitida por essa película, aplicada no acrílico de 4,0mm que compõe as faces da pirâmide, obteve-se uma taxa de aproximadamente $117,3 \%$ maior de lux detectado por reflexão em comparação a face sem película. Como resultado preliminar, conforme ilustrado pela Figura 11, notamos qualitativamente que houve um redução na iluminância proveniente da segunda imagem refletida pela pirâmide, mas ainda era possível observar a olho nu as duas imagens. Para efeito de teste, aplicamos em uma outra face da pirâmide duas películas sobrepostas. Repetimos esse procedimento para todas as faces, produzindo uma pirâmide quadrangular com um lado sem película e os demais com película simples, dupla e tripla, respectivamente.

Nota-se que o efeito de duplicata da imagem principal reduziu-se consideravelmente na face que estava com três películas sobrepostas. Qual seria a função dessas películas? Por que elas puderam ser empregadas para resolver o problema? Tais questões podem ser respondidas quando nos atentamos para a variação da iluminância do raio refratado e refletido pela película.

Através do luxímetro e efetuando as medidas dentro dos mesmos parâmetros, mantendo para cada medida a mesma distância entre o sensor e a superfície, detectou-se uma redução de aproximadamente $83,0 \%$ da quantidade de lux proveniente do raio de luz refratado $\left(R_{r r}\right)$ na face com película tripla em comparação com a face sem película. Em linhas gerais, pode-se afirmar que essa camada de películas sobrepostas funcionou como um filtro, bloqueando praticamente toda a refração e reflexão in-

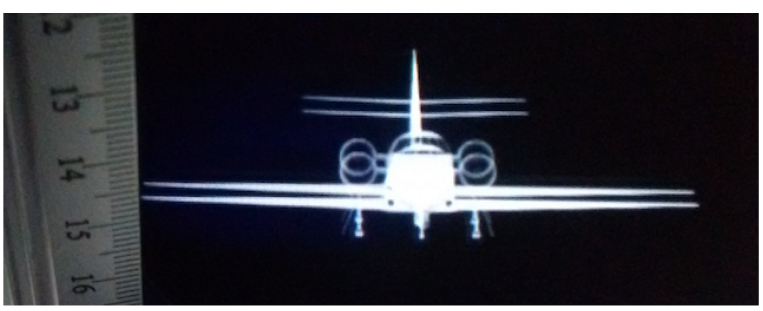

(a)

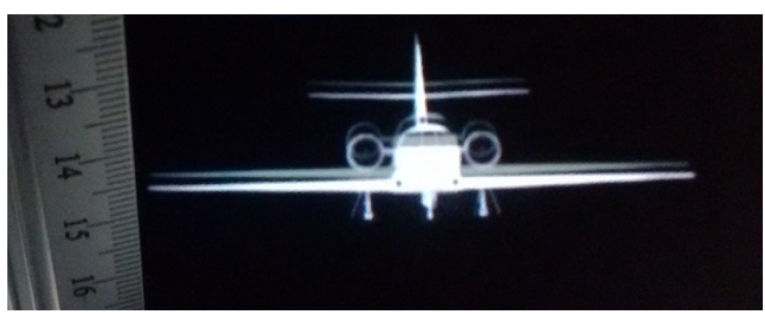

(b)

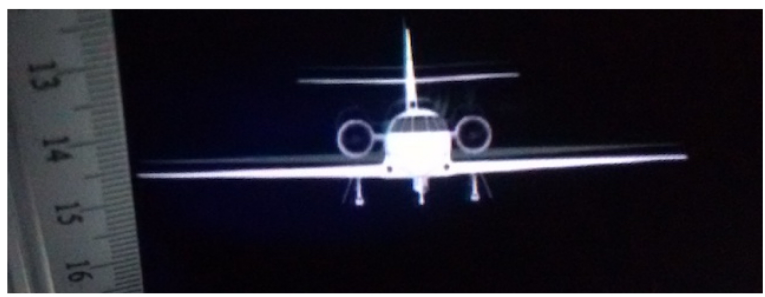

(c)

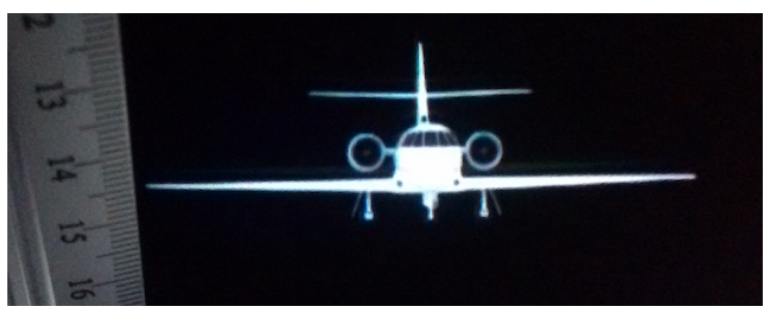

(d)

Figura 11: Imagens refletidas pela pirâmide sem e após aplicação da película automotiva. a) imagem refletida pela face sem película. b) Imagem refletida pela face com aplicação de uma única película automotiva. c) Imagem refletida pela face com aplicação de duas películas sobrepostas. d) Imagem refletida pela face com aplicação de três películas sobrepostas. Fonte: Autoria própria.

terna que resultava no feixe de luz $R_{r l r}$. Somado a isso, conforme esperado, nossos testes com o Luxímetro revelaram que o raio incidente ao atingir a superfície da pirâmide $\left(R_{i}\right)$ apresentou uma quantidade total de lux detectada por reflexão cerca de $244,2 \%$ maior com a película tripla (três películas \#2 sobrepostas) em comparação com a face transparente, ou seja, sem aplicação de película, como se esse raio tivesse atingido uma superfície parcialmente espelhada.

\section{Considerações finais}

É possível investigar ainda as implicações do uso de materiais como vidros fumê e películas de projeção, além de 
explorar outras possibilidades de montagens com base na técnica de Pepper. Todavia, acreditamos que este artigo atingiu seu objetivo principal ao evidenciar o potencial didático das pirâmides "holográficas" para o ensino de física, além de destacar os elementos físicos e conceituais presentes nesses mecanismos. Desde a discussão conceitual sobre o que são de fato os hologramas até a busca por soluções para sanar o problema da imagem duplicada, as pirâmides se mostraram um interessante instrumento no ensino de conceitos da óptica geométrica e da matemática, bem como dos processos e etapas que envolvem a resolução de um problema de investigação. Sua inserção na sala de aula pode ocorrer através dos momentos pedagógicos, conforme indicamos em algumas partes deste artigo. Além disso, os aspectos lúdicos intrínsecos a esses dispositivos os tornam um recurso valioso para instigar e fomentar a transição da curiosidade ingênua dos indivíduos a uma curiosidade epistemológica, promovendo a consciência crítica dos docentes e educandos, em geral, frente aos artefatos tecnológicos em constante mudanças ao seu redor, especialmente aqueles supostamente relacionados aos hologramas.

\section{Agradecimentos}

Agradecemos aos estudantes do Programa Institucional de Bolsas de Iniciação à Docência (PIBID) da UFRN, subprojeto Física, pelo apoio nas oficinas e exposição referente a pirâmide "holográfica" na Escola Estadual Edgar Barbosa e durante a XXII e XXIII Semana de Ciência, Tecnologia e Cultura (CIENTEC/ UFRN). Também agradecemos a Professora Juliana Mesquita Hidalgo Ferreira, ao Professor Wallas Cabral de Souza e a Professora Patricia Adna E. Takehisa pelas leituras e observações que contribuíram para a melhoria do texto.

\section{Referências}

[1] Resident Evil: O Hóspede maldito. Direção: Paul W.S. Anderson. Produção: Bernd Eichinger, Samuel Hadida, Jeremy Bolt e Paul W. S. Anderson. Companhias produtoras: Constantin Film New Legacy Films, Davis Films, Impact Pictures e Capcom (2002).

[2] Star Wars Episode IV: A New Hope. Direção: George Lucas. Produção: Gary Kurtz. Companhia produtora: Lucasfilm, (1977).

[3] Prometheus. Direção: Ridley Scott. Produção: David Giler, Walter Hill, Ridley Scott e Tony Scott. Companhias produtoras: Scott Free Productions e Brandywine Productions, (2012).

[4] Avatar. Direção: James Cameron. Produção: James Cameron e Jon Landau. Companhia produtora: Lightstorm Entertainment, (2009).

[5] Homem de Ferro 2. Direção: Jon Favreau. Produção: Kevin Feige. Companhias produtoras: Marvel Studios e Fairview Entertainment, (2010).

[6] P. Freire, Pedagogia da Autonomia: Saberes Necessários à Prática Educativa (Editora Paz e Terra. São Paulo, 1996), 36 a edição.
[7] A. Beléndez, Rev. Bras. Ensino Fís. 31, 1 (2009).

[8] M.H. Nussenzveig, Curso de Física: Ótica, Relatividade e Física Quântica - Vol. 4 (Editora Blucher, São Paulo, 1998), $1^{\mathrm{a}}$ ed.

[9] J.J. Lunazzi, Ciência hoje, 3(16), 36 (1985).

[10] Unicamp, Holografia. Laboratório de Ensino de Óptica, disponível em http://sites.ifi.unicamp.br/ laboptica/holografia-2/, acesso em 02 de maio de 2017.

[11] G. Saxby, Practical Holography (CRC Press, Boca Raton, 2015), 4th ed.

[12] R.S. Toledo, A.M. Yeras, G.V. Cruz, I.A. Pérez, D.S. Magalhaes, M. Muramatsu, et al., Rev. Bras. Ensino Fís., 36, 1 (2014).

[13] J.J. Lunazzi, "Pesquisa". Sites de Páginas Pessoais, Grupos, Disciplinas, Laboratórios e Eventos do IFGWUnicamp, disponível em: http://sites.ifi.unicamp br/lunazzi/pesquisa/, acesso em 02 de agosto de 2017.

[14] J.J. Lunazzi, in: 4th International Conference on Holographic Systems, Components and Applications (Neuchatel, Switzerland, september, 1993) pp. 153-156.

[15] E.G. da Fonseca, Dois Sistemas para Animação Holográfica. Dissertação de Mestrado, UNICAMP, Campinas, 1998.

[16] Y. Pan, J. Liu, X. Li, and Y. Wang, IEEE Transactions on Industrial Informatics, 12, 4, (2016).

[17] Revista Galileu, Holograma $3 D$ é Popstar no Japão, disponível em http://revistagalileu.globo.com/ Revista/Common/0, , EMI187440-17770, 00-HOLOGRAMA+ D+E+POPSTAR+NO+JAPAD.html, acesso em 28 de março de 2017.

[18] J.J. Lunazzi, Holograma. - Correio do Leitor, Jornal Correio Popular (2013), disponível em http://correio.rac com.br/mobile/materia_historico.php?id=40493\#, acesso em 28 de março de 2017.

[19] BBC NEWS, London Luton Airport Introduces Holographic Announcers, disponível em http://news.bbc co.uk/go/pr/fr/-/local/threecounties/hi/people_ and_places/newsid_9382000/9382178.stm, acesso em 28 de março de 2017.

[20] Bird Strategy, In This Mall, Holograms of Disabled People Appear If You Try to Park in Their Space, disponível em: https://youtu.be/DUfcNNv3g68 Acesso em 28 de março de 2017.

[21] A. Medeiros, Caderno Brasileiro de Ensino de Física 23, 329 (2008).

[22] E.E. Barcellos and G.B. Junior, Procedia Manufacturing, 3, 754 (2015).

[23] E.C. Ricardo, Problematização e Contextualização no Ensino de Física (Cengage Learning, São Paulo, 2010), p. 29-51.

[24] D. Delizoicov, in: Ensino de Física: Conteúdo, Metodologia e Epistemologia em uma Concepção Integradora, org. por Maurício Pietrocola (Editora UFSC, Florianópolis, 2005), $2^{\mathrm{a}}$ ed.

[25] D. Delizoicov, Conhecimento, Tensões e Transições. Tese de Doutorado, Faculdade de Educação, Universidade de São Paulo (1991)

[26] J.A. Angotti and D. Delizoicov, Metodologia do Ensino de Ciências (Editora Cortez, São Paulo, 2002), $2^{\mathrm{a}}$ ed. 